\title{
A GESTÃO PÚBLICA E O REUNI: ENTRE O SOCIAL E O GERENCIAL
}

1 - MSc. Diego César Terra de Andrade - Instituto Federal de Educação, Ciência e Tecnologia do Sul de Minas Gerais / Campus Pouso Alegre - diego.terra@ifsuldeminas.edu.br

2 - MSc. Conrado Gomide de Castro - Instituto Federal de Educação, Ciência e Tecnologia do Norte de Minas Gerais / Campus Arinos, conrado.gomide@ifnmg.edu.br 3 - Dr. Mônica Carvalho Alves Cappelle - Universidade Federal de Lavras - edmo@ dae.ufla.br 4 - Dr. José Roberto Pereira - Universidade Federal de Lavras - jpereira@ dae.ufla.br

Resumo: Com este artigo, objetiva-se analisar as características da gestão da política de educação superior, em vigência no Brasil, no que tange as Instituições Federais de Ensino Superior - IFES e o Programa de Apoio a Planos de Reestruturação e Expansão das Universidades Federais - REUNI, bem como suas consequências limitantes a uma educação de qualidade. A partir disso, adotou-se, como recurso metodológico, revisão bibliográfica sobre as principais características da Reforma do Estado e pesquisa documental dos pontos abordados no Decreto $\mathrm{n}^{\circ}$. 6.096, trabalhando principalmente com dados coletados em documentos oficiais e sites do governo federal. Concluiu-se que, apesar da grande proporção de investimentos, contratações e do discurso social presente no decreto, a reforma do ensino superior, em curso nas IFES, é orientada por características de políticas macroeconômicas no que tange à reestruturação da produção e à Reforma do Estado, no mesmo sentido das que vem sendo implementada nas últimas décadas no país.

Palavras-chave: REUNI; neoliberalismo; gerencialismo.

\section{THE PUBLIC MANAGEMENT AND THE REUNI: BETWEEN THE SOCIAL AND THE MANAGERIAL}

\begin{abstract}
With this article, aims to analyze the characteristics of the public management of higher education policy in force in Brazil, in terms of the Federal Institutions of Higher Education - IFES and the Support Program for the Restructuring and Expansion of Federal Universities - REUNI, and the restrictions consequences to a quality education. From there, was adopted, as a methodological resource, a review of the key characteristics of State Reform and documentary research of the points addressed in the Decree. 6096, working mainly with data collected form official documents and sites of federal government. It was concluded that despite the large proportion of investment, hiring and the social discourse in this Decree, the reform in the higher education, taking place in the IFES, is guided by characteristics of macroeconomic policies in regard to the restructuring of production and the Reformation State in the same sense of what has been implemented in recent decades in the country.
\end{abstract}

Key words: REUNI; neoliberalism; managerialism.

\section{Introdução}

A chegada da grande crise do modelo econômico no pós-guerra, quando o mundo capitalista avançado caiu numa longa e profunda recessão, mais especificamente em 1973, combinando, pela primeira vez, baixas taxas de crescimento com altas taxas de inflação, trouxe significativas mudanças na economia global. A partir daí as idéias neoliberais passaram a ganhar terreno (ANDERSON, 1995). A crítica ao Estado intervencionista, efetivada pelos 
partidários do neoliberalismo, e a busca de minimização da atuação do Estado no tocante às políticas sociais, pela redução ou desmonte das políticas de proteção, são prescritas como caminho para a retomada do desenvolvimento econômico por meio da Reforma do Estado. A defesa ideológica dessa reforma é implementada pelo discurso de modernização e racionalização do Estado ("Estado Mínimo”), objetivando, desse modo, a superação das mazelas do mundo contemporâneo (desemprego, hiperinflação, redução do crescimento econômico...) e de adaptação às novas demandas pelo processo de globalização que se iniciava (CARDOSO, 2006, p. 15).

No Brasil, a Reforma do Estado tem inicio no ano de $1995^{1}$, durante o mandato presidencial de Fernando Henrique Cardoso (FHC) (REZENDE, 2002) e é encabeçada pelo então ministro da Administração Federal e Reforma do Estado, Luiz Carlos Bresser Pereira. De acordo com Filho (2004), estas mudanças estão baseadas no princípio geral de elevação do desempenho do setor público, sendo que o grande desafio para este setor

\footnotetext{
$1 \mathrm{Na}$ constituição de 1988 e no governo Collor/Itamar, tem-se um contorno de uma reforma gerencial do estado, entretanto, apenas no governo Cardoso ela se efetiva, com a reforma do aparelho do Estado, na dimensão-gestão, que foi realizada através de uma série de projetos conduzidos pelo Ministério da Administração Federal e da Reforma do Estado - MARE (REZENDE, 2002).
}

é criar um sistema eficiente e de boa qualidade na provisão dos serviços públicos. Nestes anos, a reforma do sistema de educação superior no país ocorreu em paralelo a estas reformas do Estado, priorizando o livre jogo do mercado. Ou seja, durante os dois mandatos de Fernando Henrique Cardoso (1995-2002) houve um forte processo de mercadorização das relações sociais, inclusive da educação (LIMA, AZEVEDO \& CATANI, 2008).

$$
\text { Para Lima (2009) o governo }
$$

Cardoso desenvolveu sua concepção sobre o papel da educação, especialmente da educação superior, a crescente desresponsabilização do Estado com a Universidade através da redução de verbas públicas para seu financiamento e, simultaneamente, do estímulo ao empresariamento deste nível de ensino, sob a aparência de democratização do acesso à educação. A autora conclui que estes elementos estão presentes na reformulação da educação superior, realizada nos dois mandatos de FHC. Vários autores como Otranto (2004), Mancebo (2004), Santos (2005), Frigotto (2005), Chaves (2006), Mancebo, Maués e Chaves (2006), Boschetti (2007), Cunha (2007), entre outros, afirmam que o Governo Lula apenas dá continuidade as ações empreitadas pelo governo de Fernando 
Henrique Cardoso, no que tange a educação pública superior.

Diante de tal afirmação tem-se o seguinte problema: como está sendo gestada à política de educação nas Instituições Federais de Ensino Superior (IFES) em nosso país, através do Decreto $n^{\circ}$. 6.096 que instituiu o Programa de Apoio a Planos de Reestruturação e Expansão das Universidades Federais REUNI, que por sua vez é integrante do Plano de Desenvolvimento da Educação PDE?

Portanto, o objetivo deste trabalho é analisar as características da gestão da política de educação superior do Brasil, no que tange as IFES e ao REUNI, e suas consequências limitadoras a uma educação de qualidade. Neste intuito será realizada uma revisão bibliográfica, sobre as principais características da Reforma do Estado e os pontos abordados no Decreto $\mathrm{n}^{\circ}$. 6.096 que possui números como: previsão de contratação de 15.755 novos professores, 13.564 novos técnicos administrativos e investimento da ordem de 2,07 bilhões de reais (MEC, 2009).

Adotou-se, como recurso metodológico, a pesquisa bibliográfica e documental, trabalhando principalmente com dados coletados em documentos oficiais e sites do governo federal.

\section{Governo Neoliberal e Administração Pública Gerencial}

O neoliberalismo ganhou força a partir da década de 80 , principalmente com as políticas introduzidas inicialmente nos Estados Unidos com o governo de Ronald Reagan e na Inglaterra com Margareth Thatcher, onde foram apresentadas ao mundo como a única solução possível para o desenvolvimento da economia mundial. Dentre as instituições que deram força e apoio a esta nova forma de governo, têmse o Fundo Monetário Internacional (FMI), o Banco Mundial (BIRD), a Organização Mundial do Comércio (OMC) e o G-7, atualmente G-8 (considerado o grupo dos países mais ricos e industrializados do mundo, a saber: EUA, Japão, Alemanha, França, Reino Unido, Itália, Canadá e a Rússia). Os ideais neoliberais, fundamentados no liberalismo econômico, primaram pela abertura dos mercados, privatização, redução da intervenção estatal (estado mínimo) e dos gastos sociais (LEITE, 2003).

Kettl (2006) traz que, na atualidade, como um dos efeitos da era da informação, os cidadãos no mundo inteiro, assim como também seus representantes eleitos, parecem simplesmente ter chegado à conclusão de que o governo de seu país, seja qual for o seu tamanho relativo, é grande demais e precisa ser reduzido, além 
do que a administração pública é muito cara e deve ser modificada para oferecer maior eficiência e eficácia.

Com isso, tem-se a segunda geração de governos neoliberais (na década de 90), a qual acentuou a gestão da globalização mercantil exercida pelas instituições multilaterais - FMI, Banco Mundial e OMC - que sedimentaram o Consenso de Washington, que pode ser encarado como um receituário de medidas de caráter neoliberal para promover o "ajustamento macroeconômico" dos países em desenvolvimento (que naquele momento passavam por dificuldades), formuladas por economistas destas instituições financeiras que estavam localizadas em Washington (GONÇALVES \& SILVA, 2009). Contudo, no Brasil, essas reformas ocorreram em única instância.

A partir dessas idéias observa-se que a maioria das nações começaram a reduzir sua estrutura ou cortar as "pontas soltas" da administração pública, por meio de inúmeros mecanismos, como: limitação das dimensões do setor público; privatização; comercialização ou corporatização de órgãos públicos; descentralização para governos subnacionais; desconcentração no governo central; uso de mecanismos típicos de mercado; novas atribuições aos órgãos da administração central; e outras iniciativas de reestruturação ou "racionalização" (KETTL, 2006, p.78).

Sendo assim, Matias-Pereira (2008) observa que "no processo de transformação institucional" no setor público brasileiro, orientado nos últimos 15 anos, prevalece à visão do paradigma neoliberal, tendo como referência a preocupação com o "ajuste fiscal." Tem-se então, de acordo com Chaves, Lima e Medeiros (2006), que a redução dos investimentos públicos e a defesa da diversificação das fontes de financiamento foram centrais na reforma da educação superior adotada no país. Essa reforma cumpre as orientações do Banco Mundial que apresenta como uma das teses a de que a crise da educação brasileira deriva do modelo de universidade de pesquisa, o qual é excessivamente unificado e caro.

Com a redemocratização no Brasil e a Reforma do Estado tem-se procurado construir um modelo de gestão pública capaz de atender às necessidades dos cidadãos, proporcionar maior transparência pública e se tornar mais eficiente na coordenação da economia e dos serviços públicos (PAES DE PAULA, 2005).

Sendo assim, de acordo com Bresser-Pereira (2006), o modelo gerencial surge, principalmente, como resposta à grande crise financeira dos anos 80 caracterizada principalmente pela redução no PIB, o aumento inflacionário no Brasil 
e à globalização. Tem-se então, que devidos a esses problemas advindos da crise o governo até então militar perde força levando à eleição de um presidente civil de maneira indireta abrindo as portas para a democracia, o que consequentemente leva o país a rever seu estilo de gestão implantando ferramentas mais modernas.

A partir da década de 1990, principalmente com o governo de Fernando Henrique Cardoso o modelo gerencial vem se despontando como um novo modelo de gestão pública, o qual busca uma ampliação da democracia no país. Para Paes de Paula (2005), ainda no governo subseqüente, o do atual presidente Lula, observa-se uma continuidade das práticas gerencialistas em todos os campos, inclusive no que se refere às políticas sociais. No entanto, segundo Paes de Paula (2005, p. 37) "ocorreu um desapontamento em relação aos indicadores de crescimento econômico e progresso social obtidos".

Bresser-Pereira (1998) afirma que os principais objetivos da administração pública gerencial são: melhorar as decisões estratégicas do governo e da burocracia; garantir a propriedade e o contrato, promovendo um bom funcionamento dos mercados; garantir a autonomia e capacitação gerencial do administrador público e assegurar a democracia através da prestação de serviços públicos orientados para o cidadão-cliente e controlados pela sociedade. Para tanto, ele advoga que para que o modelo tenha êxito deve-se enfatizar a profissionalização e o uso de práticas de gestão do setor privado.

Bresser-Pereira (2006) mostra que a idéia de uma administração pública gerencial no Brasil é antiga. Ele traz que em 1938 há a criação da primeira autarquia, onde se surge a idéia de que "os serviços públicos na administração indireta deveriam ser descentralizados e não obedecer a todos os requisitos burocráticos da administração direta ou central" (BRESSER-PEREIRA, 2006 p. 243).

Ainda de acordo com este mesmo autor a reforma ou transição de uma forma de governo burocrática para uma gerencial não deve ser de forma abrupta, ou seja, da noite para o dia. Ele coloca também que a burocracia tem seu mérito como sua segurança e efetividade devendo ela ser mantida no núcleo estratégico onde estas características são importantes, além do que, ela deve estar presente, em conjunto com a administração pública gerencial.

Outra característica do gerencialismo que pode ser destacada são os contratos de gestão, onde se tem um núcleo estratégico que define os objetivos das entidades executoras do Estado e os respectivos indicadores de desempenho, além de garantir a essas entidades os meios humanos, materiais e financeiros para sua 
operação. No entanto, Bresser-Pereira (2006) coloca que certas instituições burocráticas como exigência de concurso ou processo de seleção público, um sistema universal de remuneração, carreiras formalmente estruturadas e um sistema de treinamento devem existir. Só que este treinamento deve estar relacionado e alinhado com as necessidades do novo Estado que se quer implantar, ao invés subordinar-se às etapas de uma carreira, como deseja a visão burocrática.

Paes de Paula (2005) destaca os principais elementos relacionados à Administração Pública Gerencial, sistematizados na figura 01 .

\begin{tabular}{|c|c|}
\hline Origem & $\begin{array}{l}\text { Movimento internacional pela } \\
\text { reforma do Estado, que se iniciou } \\
\text { nos anos } 80 \text { e se baseia } \\
\text { principalmente nos modelos inglês e } \\
\text { estadunidense }\end{array}$ \\
\hline $\begin{array}{l}\text { Projeto } \\
\text { Político }\end{array}$ & $\begin{array}{l}\text { Enfatiza a eficiência administrativa } \\
\text { e se baseia no ajuste estrutural, nas } \\
\text { recomendações dos organismos } \\
\text { multilaterais internacionais e no } \\
\text { movimento gerencialista }\end{array}$ \\
\hline $\begin{array}{l}\text { Dimensões } \\
\text { estruturais } \\
\text { enfatizadas } \\
\text { na gestão }\end{array}$ & $\begin{array}{l}\text { Dimensões econômico-financeira e } \\
\text { institucional-administrativa }\end{array}$ \\
\hline $\begin{array}{l}\text { Organizaçã } \\
\text { o } \\
\text { Administra } \\
\text { tiva do } \\
\text { Aparelho } \\
\text { do Estado } \\
\end{array}$ & $\begin{array}{llll}\text { Separação } & \text { entre } & \text { as atividades } \\
\text { exclusivas e não-exclusivas dos } \\
\text { Estados nos três níveis } \\
\text { governamentais }\end{array}$ \\
\hline $\begin{array}{l}\text { Abertura } \\
\text { das } \\
\text { instituições } \\
\text { políticas à } \\
\text { participaçã } \\
\text { o social }\end{array}$ & $\begin{array}{l}\text { Participativo no nível do discurso, } \\
\text { mas centralizador no que se refere } \\
\text { ao processo decisório, à organização } \\
\text { das instituições políticas e à } \\
\text { construção de canais de participação } \\
\text { popular }\end{array}$ \\
\hline $\begin{array}{l}\text { Abordagem } \\
\text { de gestão }\end{array}$ & $\begin{array}{l}\text { Gerencialismo: enfatiza a adaptação } \\
\text { das recomendações gerencialistas } \\
\text { para o setor público }\end{array}$ \\
\hline
\end{tabular}

Figura 01 - Administração Pública Gerencial Fonte: Adaptado de Paes de Paula, 2005.
Na visão de Paes de Paula (2005), a administração pública de estilo gerencial, apresenta características que a aproximam, fortemente, daquela praticada por empresas privadas com fins lucrativos, porém aplicada a organizações que possuem outras finalidades, como é o caso encontrado nas universidades públicas.

Neste sentido, Chauí (1999), afirma que a universidade federal estaria passando da condição de instituição social para organização social.

A universidade sempre foi uma instituição social, isto é, uma ação social, uma prática social fundada no reconhecimento público de sua legitimidade ou de suas atribuições, num princípio de diferenciação, que lhe confere autonomia perante outras instituições sociais, e estruturadas por ordenamentos, regras, normas e valores de reconhecimento e de legitimidade internas a ela. (CHAUÍ, 1999, p.3).

Para a mesma autora, "uma organização social difere de uma instituição por definir-se por outra prática social, qual seja, a de sua instrumentalidade: está referida ao conjunto dos meios particulares para obtenção de um objetivo particular". A organização social "não está referida a ações articuladas às idéias de reconhecimento interno e externo, de legitimidade interna e externa, mas a operações definidas como estratégias balizadas pelas idéias de eficácia e sucesso 
no emprego de determinados meios para alcançar o objetivo particular que a define" (CHAUÍ, 1999, p.3).

Com isto, os modelos de administração pública de estilo gerencialista, que vem sendo adotados, já há algum tempo, pelos governos federais nas universidades públicas (OTRANTO, 2004; MANCEBO, 2004; SANTOS, 2005; FRIGOTTO， 2005; CHAVES， 2006; MANCEBO, MAUÉS e CHAVES, 2006; BOSCHETTI, 2007; CUNHA， 2007), como modalidade de ajuste a ser celebrado, transformam estas instituições em organizações sociais (CHAVES \& MENDES, 2009). Como conseqüência a "universidade operacional" - termo cunhado por Freitag para classificar a universidade, como organização social (CF. LE NAUFRAGE DE L'UNIVERSITÉ apud CHAUÍ, 2003) passaria a ter as seguintes características:

Regida por contratos de gestão, avaliada por índices de produtividade, calculada para ser flexível, a universidade operacional está estruturada por estratégias e programas de eficácia organizacional e, portanto, pela particularidade e instabilidade dos meios e dos objetivos. Definida e estruturada por normas e padrões inteiramente alheios ao conhecimento e à formação intelectual, está pulverizada em micro organizações que ocupam seus docentes e curvam seus estudantes a exigências exteriores ao trabalho intelectual. (CHAUÍ, 2003, p.3).
Dessa maneira, institucionaliza-se um novo ethos acadêmico, onde critérios de produtividade e eficácia organizacional se sobrepõem aos objetivos da instituição social caracterizada pela universalidade na produção e transmissão da experiência cultural e científica da sociedade e pela liberdade de discussão e espírito crítico, para configurá-la como organização social, transformando a universidade numa “organização prestadora de serviços”, com estrutura de gestão voltada para a arbitragem de contratos. Consagrando-se assim, a idéia da universidade "moderna e produtiva" (CHAVES \& MENDES, 2009). Chauí (1999), corrobora com estas autoras, ao falar que a universidade operacional, é fruto da modernização e racionalização do Estado.

Chauí (1999), diz ainda, que o pressuposto ideológico dessa proposição é o que expressa o entendimento de que o mercado é o portador da racionalidade necessária ao bem-estar da República, o qual deve ocorrer sob o signo da "flexibilização". E adverte que, para o Ministério da Educação, "flexibilizar" significa, entre outras coisas: eliminar o regime único de trabalho, o concurso público e a dedicação exclusiva, substituindo-os por "contratos flexíveis", isto é, temporários e precários; adaptar os currículos de graduação e pós-graduação às necessidades profissionais das diferentes 
regiões do país, ou seja, às demandas das empresas locais; separar docência e pesquisa, deixando à primeira na universidade e deslocando a segunda para centros autônomos.

Desse modo, a universidade operacional está do lado oposto daquilo que assegura a constituição brasileira sobre a autonomia universitária, além de suas três frentes de atividades: ensino, pesquisa e extensão (SAVATER, 2000). Fávero (2008) ao discutir a autonomia universitária no Brasil, acrescenta que ela, até este momento da história de nosso país, ainda não existiu, pois sempre esteve condicionada a algum tipo de "ancora". O que no caso especifico deste contexto pode-se afirmar que advém de um novo modelo de gestão pública baseado em números em detrimento da qualidade, o chamado "fetiche da gestão por resultados" (SHIROMA, et al., 2008).

\section{Programa de Apoio a Planos de} Reestruturação e Expansão das Universidades Federais - REUNI

Em 24 de abril de 2007, foi lançado, pelo Governo Federal, o Plano de Desenvolvimento da Educação - PDE que contém cerca de quatro dezenas de medidas, entre elas o Decreto $n^{\circ}$. 6.096 que institui o Programa de Apoio a Planos de Reestruturação e Expansão das
Universidades Federais - REUNI. Este decreto dirige-se especificamente às IFES, cujo histórico merece apreciação mais detida.

Em 1998, em Paris, os ministros da educação da Alemanha, França, Itália e Reino Unido assinaram uma declaração conjunta com vistas à construção de um "espaço europeu de educação superior" (DECLARAÇÃO DA SORBONNE, 1998). No ano seguinte, os ministros de vinte e nove estados europeus, incluindo Portugal, subscreveram a chamada Declaração de Bolonha, onde assumem como objetivos o estabelecimento, até o ano de 2010, de um espaço europeu de educação superior coerente, compatível, competitivo e atrativo para estudantes naturais da Europa e advindos de outros continentes. Atualmente encontram-se nesta reformulação quarenta e cinco países isto é, todos os países da União Européia (UE) e, ainda, dezessete países europeus não pertencentes à UE (Albânia, Alemanha, Andorra, Armênia, Azerbaijão, Áustria, Bélgica (comunidades flamenga e francófona), Bósnia e Herzegovina, Bulgária, Chipre, Croácia, Dinamarca, Eslováquia, Eslovênia, Espanha, Estónia, Finlândia, França, Geórgia, Grécia, Hungria, Islândia, Irlanda, Itália, Letônia, Lituânia, Liechtenstein, Luxemburgo, Macedônia, Malta, Moldávia, Montenegro, Noruega, Países Baixos, Polônia, Portugal, 
Romênia, Rússia, Santa Sé, Sérvia, Suécia, Suíça, Turquia, Reino Unido, República Checa e Ucrânia) (CATANI, AZEVEDO \& LIMA, 2008).

A construção do referido sistema europeu de educação superior é considerada "a chave para promover a mobilidade e a empregabilidade dos cidadãos e para a obtenção de maior compatibilidade e de maior comparabilidade". Embora, ainda de acordo com Catani, Azevedo e Lima (2008), se recuse a idéia de simples homogeneização ou padronização, eventualmente menos aceitável face à grande diversidade da educação superior dos países aderentes, insiste-se na harmonização e na necessidade da coordenação de políticas, na promoção da dimensão européia dos currículos, na cooperação internacional, na mobilidade e no intercâmbio, bem como na cooperação no "setor da avaliação da qualidade", tendo em vista vir a desenvolver critérios e metodologias que sejam passíveis de comparação (DECLARAÇÃO DE BOLONHA, 1999).

Já no Brasil, no segundo semestre de 2006, inicia-se uma campanha contra o atual formato do ensino ministrado na maioria das universidades, com diagnósticos e análises variados, baseados em dados estatísticos das vagas nas universidades públicas e das altas taxas de evasão no ensino superior. A proposta apresentada para se contrapor a esse quadro teve, na ocasião, como principal interlocutor o reitor da Universidade Federal da Bahia, professor Naomar Monteiro de Almeida Filho que, em inúmeras visitas, aulas inaugurais e palestras, divulgou a chamada "Universidade Nova" como a solução contra a obsolescência das universidades de modelo tradicional.

Em apresentação no II Seminário o Prof. Naomar (Universidade Nova: Descrição da Proposta, 2007, p. 17), afirma que:

a idéia de estudos superiores de
graduação de maior amplitude e não
comprometidos com uma
profissionalização precoce r e
fechada, bem como maior
integração entre esses estudos e os
de pós-graduação, já é realidade em
muitos países social e
economicamente desenvolvidos. O
processo europeu de Bolonha é um
exemplo eloqüente dessa concepção
acadêmica que, por força das
demandas da Sociedade do
Conhecimento e de um mundo do
trabalho pero marcado pela
desregulamentação, flexibilidade e
imprevisibilidade, certamente se
consolidará como um dos modelos
de educação superior de referência
para o futuro próximo.

Por tanto, conclui-se que a proposta denominada "Universidade Nova" possui clara similaridade com processo europeu, que por sua vez, de acordo com Léda e Mancebo (2009), teve a possibilidade de materialização, em âmbito nacional, com a publicação do Decreto nº 6.096. 
$\mathrm{O}$ artigo $1^{\circ}$ e parágrafo $1^{\circ}$, do mesmo artigo, definem o objetivo e a meta global do REUNI. Nos termos do Decreto:

Art. $1^{\circ}$ Fica instituído o Programa de Apoio a Planos de Reestruturação e Expansão das Universidades Federais - REUNI, com o objetivo de criar condições para a ampliação do acesso e permanência na educação superior, no nível de graduação, pelo melhor aproveitamento da estrutura física e de recursos humanos existentes nas universidades federais.

$\S 1^{\circ} \mathrm{O}$ Programa tem como meta global a elevação gradual da taxa de conclusão média dos cursos de graduação presenciais para noventa por cento e da relação de alunos de graduação em cursos presenciais por professor para dezoito, ao final de cinco anos, a contar do início de cada plano.

$\mathrm{O}$ Artigo $5^{\circ}$ diz que: "O ingresso no Programa poderá ser solicitado pela IFES, a qualquer tempo, mediante proposta instruída”, ou seja, sua adesão é facultativa, contudo, as 53 Universidades Federais o fizeram (MEC, 2009). O REUNI condiciona o financiamento ao cumprimento de metas previamente acordadas. Segundo o referido decreto, "A proposta, se aprovada pelo Ministério da Educação, dará origem a instrumentos próprios, que fixarão os recursos financeiros adicionais destinados à universidade, vinculando os repasses ao cumprimento de etapas" (Art. $6^{\circ}$ ).

Estes instrumentos são contratos de gestão, firmados entre as universidades públicas federais e o governo, por meio do estabelecimento de um Termo de Compromisso, denominado "Acordo de Metas". Como exemplo, logo que a instituição faça sua adesão ao programa, cria-se o compromisso em contemplar o aumento mínimo de $20 \%$ nas matrículas de graduação, ao final de até cinco anos.

Os recursos financeiros para que as modificações orientadas por estas diretrizes sejam efetivadas, de acordo com o MEC (2007), serão custeados pelo Tesouro e, incluem a contratação de 15.755 novos professores, 13.564 novos técnicos administrativos, bolsas para alunos de pós-graduação e outras despesas (MEC, 2009) no montante total de dois bilhões de reais adicionais, a serem incorporados permanentemente ao orçamento das Universidades. Com relação aos investimentos em espaço adicional e equipamentos, que devem ser efetuados, ao longo dos primeiros cinco anos, somam-se, ainda, mais 2,07 bilhões de Reais (MEC, 2009). Entretanto, conforme artigo $3^{\circ}$ as verbas serão concedidas "na medida da elaboração e apresentação dos respectivos planos de reestruturação".

Demonstrando o predomínio das finanças, sobre a educação, o REUNI está limitado à previsão orçamentária concedida. Assim, o Ministério da Educação subordina as IFES, e conseqüentemente, o projeto de 
implantação da "Universidade Nova", aos Ministérios do Planejamento e da Fazenda. Ou seja, os artigos $3^{\circ}, 5^{\circ}$ e $6^{\circ}$, do referido decreto, corroboram com o que pode ser entendido, de acordo com Paes de Paula (2005) como um dos pressupostos encontrados na administração pública gerencial, uma vez que as ações possuem cunho "participativo no nível do discurso, mas centralizador no que se refere ao processo decisório", condicionando os recursos a metas (OTRANTO, 2004; MANCEBO, 2004; SANTOS, 2005; FRIGOTTO, 2005; CHAVES, 2006; MANCEBO, MAUÉS e CHAVES, 2006; BOSCHETTI, 2007; CUNHA, 2007), e na verdade não respeita o ethos de cada instituição (CHAVES \& MENDES, 2009).

Para que o programa atinja seus objetivos e metas, o artigo $2^{\circ}$ do decreto apresenta as seguintes diretrizes: "I. redução das taxas de evasão, ocupação de vagas ociosas e aumento de vagas de ingresso, especialmente no período noturno". Entende-se como vagas ociosas, as vagas disponíveis nos cursos de graduação decorrentes de não preenchimento inicial, de abandono ou desligamento dos alunos. $\mathrm{O}$ programa pretende congregar esforços no sentido da expansão da educação superior pública e é visto como um importante auxiliar para se atingir a meta de $30 \%$ de matrícula dos jovens na faixa etária de 18 a 24 anos, até o fim desta década. Os principais meios para se chegar a esta meta são aumentar a taxa de conclusão média em cursos de graduação para 90\%, a relação de aluno para cada professor e a criação de cursos noturnos para melhor aproveitamento das estruturas físicas (MEC, 2007). Pode-se concluir que o MEC entende que existe capacidade ociosa no sistema, que pode ser mais bem aproveitada adotando-se medidas administrativas e pedagógicas. Pela análise da administração pública de estilo gerencial, a ênfase se encontra na eficiência administrativa (PAES DE PAULA, 2005) ou ainda, de acordo com Shiroma et al. (2008) no "fetiche da gestão por resultados".

A diretriz II do mesmo artigo, diz que a "ampliação da mobilidade estudantil com a implantação de regimes curriculares e sistemas de títulos que possibilitem a construção de itinerários formativos, mediante o aproveitamento de créditos e a circulação de estudantes entre instituições, cursos e programas de educação superior". Neste programa entende-se que existam dois tipos de mobilidade estudantil. Uma delas é a mobilidade interna, que permitiria a circulação dos estudantes entre cursos, incluindo a mudança de curso na mesma instituição, com aproveitamento de estudos. Já a outra é a mobilidade externa, que permite a circulação estudantil entre instituições, também, com aproveitamento 
de estudos. A implantação de regimes curriculares diz respeito a uma (re)organização de suas características, em que haveria a indicação dos conteúdos mínimos, com fixação do período de integralização e duração de cursos. Já o sistema de títulos e os itinerários formativos estão estritamente ligados. À medida que o aluno realizar um conjunto de atividades formativas (bloco de matérias) será possível conduzi-lo à certificação ou diplomação, o que se entende por sistemas de títulos. Para Chauí (1999) a adaptação dos currículos se justificam as demandas das empresas locais, e estas características corroboram com o a orientação sobre o projeto político, nas recomendações dos organismos multilaterais internacionais e no movimento gerencialista, em que esta alicerçada a atual administração pública.

$\mathrm{Na}$ diretriz III do artigo $2^{\circ}$, tem-se "revisão da estrutura acadêmica, com reorganização dos cursos de graduação e atualização de metodologias de ensinoaprendizagem, buscando a constante elevação da qualidade", ou seja, a estrutura acadêmica prescreve uma articulação entre unidades acadêmicas, docência e execução de atividades curriculares para desenvolvimento da formação superior, possibilitada por uma reorganização dos cursos, através da construção de novos desenhos curriculares, possíveis, por exemplo, pela queda de matérias que contenha pré-requisitos, co-requisitos, disciplinas obrigatórias e o aumento da oferta de disciplinas optativas o que incentivará à diversidade do conhecimento.

A remodelação das metodologias de ensino-aprendizagem é entendida como um conjunto de atividades e procedimentos relacionados ao processo ensinoaprendizagem. Exemplos destes novos instrumentos seria a criação de programas de tutorial (monitoria on-line), do uso da educação à distância/EAD, a filmagem de aulas em disciplinas com altos índices de reprovação, entre outras. Para Chauí (1999), bem como para Chave e Mendes (2009), esta é a universidade operacional, fruto da modernização e racionalização do Estado, com vistas às orientações de eficiência e eficácia na prestação do serviço em detrimento a qualidade.

Sobre a diretriz "IV. diversificação das modalidades de graduação, preferencialmente não voltadas à profissionalização precoce e especializadas" do já referido artigo, entende-se que a diversificação das modalidades de graduação propõe uma formação genérica, com a emissão de diploma em três níveis: bacharelado geral, bacharelado interdisciplinar e bacharelado específico (apenas aqueles que chegarem à última etapa receberão diplomas de bacharelado das profissões 
regulamentadas) após um ou dois anos de formação específica. As primeiras etapas, com especializações em campos de saber (bacharelado geral e bacharelado interdisciplinar), emitirão diplomas de nível superiores não equivalentes a de graduação. Estas ações serão tomadas a fim de evitar uma profissionalização especializada resultante de formação compartimentada e extremamente focada e, também, uma profissionalização precoce. Neste sentido, Paes de Paula (2005) afirma que estas ações se baseiam no ajuste estrutural, promovendo a otimização dos recursos físicos e de pessoal.

Já a diretriz "V. ampliação de políticas de inclusão e assistência estudantil" compreende-se como promotora da inclusão estudantil, defendendo uma democratização, diversificação e ampliação do acesso à educação superior por meio de cotas a certos grupos, além de uma assistência estudantil ofertantes de meios e condições para permanência do aluno nestas instituições, por exemplo, através de bolsas e subsídio à moradia e alimentação dentro do campus. Ao induzir a criação de cursos noturnos, o REUNI, também, mostra esta preocupação com a inclusão social, pois, o aluno ao ter a opção de estudar a noite tem a possibilidade de trabalhar durante o dia, o que, teoricamente, possibilitaria sua manutenção na Universidade. Esta diretriz apóia-se, por tanto, sob o principio gerencialista de foco no cidadão cliente, ou seja, "orientado para o atendimento das demandas dos cidadãos" (BRESSERPEREIRA, 1996, p.11).

E, finalmente a diretriz "VI. articulação da graduação com a pósgraduação e da educação superior com a educação básica" que diz que o redesenho curricular dos cursos devem valorizar a flexibilização e a interdisciplinaridade, diversificando as modalidades de graduação e articulando-as com a pósgraduação, além do estabelecimento da necessária e inadiável (MEC, 2007) interface da educação superior com a educação básica - orientações já consagradas na Lei de Diretrizes Básicas de 1996 - LDB/96 e referendadas pelas Diretrizes Curriculares Nacionais, definidas pelo Conselho Nacional de Educação - CNE. Como exemplo da articulação da graduação com a pósgraduação tem-se a "inserção dos alunos de pós-graduação nos processos de docência", ou mesmo tutoria. Pode ser entendido, como o que, Chauí (1999) critica sobre o sentido que o Ministério da Educação da a "flexibilizar", afirmando que para este órgão isto significa, também, eliminar o regime único de trabalho, o concurso público e a dedicação exclusiva, substituindo-os por "contratos flexíveis", isto é, temporários e precários. 


\section{Considerações Finais}

Com este artigo objetivou-se analisar as características da gestão da política de educação superior, em vigência no Brasil, no que tange as IFES e ao REUNI. Bem como, suas consequências limitantes a uma educação de qualidade, a partir de uma revisão bibliográfica e pesquisa documental, sobre as principais características da Reforma do Estado e os pontos abordados no Decreto $\mathrm{n}^{\mathrm{o}}$. 6.096, que por sua vez é integrante do PDE. Trabalhou-se, principalmente, com dados coletados em documentos oficiais e sites do governo federal.

Apesar da grande proporção, de investimentos e contratações e do discurso social, presente no decreto, foi possível constatar-se que a reforma do ensino superior, em curso nas IFES, é orientada por características das políticas macroeconômicas no que tange à reestruturação da produção e à Reforma do Estado, no mesmo sentido das que vem sendo implementada nas últimas décadas no Brasil. Contudo, não se verificou uma desresponsabilização do Estado, nem tão pouco o estimulo ao empresariado, como ocorrido no governo Cardoso e apontado em outras pesquisas.

Assim, essas políticas estão intimamente relacionadas com a estratégia de inserção da economia brasileira nas grandes transformações que vêm ocorrendo na base produtiva do capitalismo, em âmbito mundial. Nesse sentido, tais políticas se orientam por um modelo de gestão gerencialista. Isto pode ser notado pelo fato de princípios como produtividade, eficiência baseada em ajustes estruturais, controle, accountability, dentre outros, estarem diretamente relacionados com as propostas que vem sendo implantadas nas universidades públicas por meio do REUNI.

$\mathrm{O}$ decreto, que de forma semelhante ao conceito de contrato de gestão, instrumento inspirado nas propostas do Ministério da Administração Federal e da Reforma do Estado, da época do Ministro Bresser-Pereira (BRESSER-PEREIRA \& SPINK, 2006), condiciona o financiamento ao cumprimento de metas previamente acordadas, limitam a qualidade da educação nestas instituições, pois, de acordo com Chauí (1999), quando a medida de produtividade é orientada pelos critérios de "quanto uma universidade produz, em quanto tempo e qual o custo do que se produz", não se leva em consideração "o que se produz, como se produz, para que ou para quem se produz". Consequentemente, o que está em jogo, não diz respeito à discussão sobre a democratização do saber, à idéia de formação das pessoas, o exercício da crítica, a criação cultural, o bem-estar coletivo, ou à dimensão ética do 
conhecimento. As palavras-chave deste discurso são carregadas de instrumentalidade: governança, produtividade, empregabilidade, entre outros.

Contudo, não se pode dizer que os princípios norteadores da Reforma Gerencial sejam ruins, entretanto, não cabem aos serviços do governo orientados por outros fins que não o lucro. Sendo a educação um dos "direitos sociais" (Constituição Federal, art. $6^{\circ}$ ) algumas das medidas de cunho gerencial são limitantes a sua real finalidade: a social.

Como limites desta pesquisa, bem como sugestão a estudos futuros, aplica-se a possibilidade de estudos empírico através da analise de outros documentos e pesquisas nas IFES. Ainda como sugestão, dentro do mesmo assunto, tem-se, analisar o PDE em sua integridade. Outra sugestão seria a utilização desta mesma abordagem para análise de outros serviços públicos, que não só, os de ensino.

\section{Referências}

ANDERSON, P.. Balanço do Neoliberalismo. IN: SADER, E.; GENTILI, P. (Org.) Pósneoliberalismo: as políticas sociais e o Estado democrático. Rio de Janeiro: Paz e Terra, 1995.

BIRD/BANCO MUNDIAL. La Ensanñanza Superior: Las lecciones derivadas de la experiencia. (El Desarrollo en la práctica) Washington, D.C: BIRD/BANCO MUNDIAL, 1995.

BOSCHETTI, I.. A ofensiva de desregulamentação no capitalismo contemporâneo: tendências destrutivas das reformas neoliberais no Serviço Social. Revista Em Pauta n. 2 da FSS/UERJ, 2007.

BRASIL. Constituição da República Federativa do Brasil de 1988. Disponível em $<$ http://www.planalto.gov.br/ccivil_03/const ituicao/constituiçao.htm >. Acesso em: 10 de dez. de 2009.

Lei $n^{\circ} 9.394$, de 20 de dezembro de 1996. Estabelece as diretrizes e bases da educação nacional. Disponível em < http://www.planalto.gov.br/ccivil_03/LEIS /19394.htm > . Acesso em: 10 de dez. de 2009.

Decreto $N^{\circ}$ 6.096, de 24 de abril de 2007. Disponível em < http://www.planalto.gov.br/ccivil_03/_Ato 2007-2010/2007/Decreto/D6096.htm >. Acesso em: 10 de dez. de 2009.

Ministério da Educação e do Desporto. Diretrizes gerais do Decreto 6096 - REUNI - Reestruturação e Expansão das Universidades Federais 2007. Disponível em < http://portal.mec.gov.br/sesu/arquivos/pdf/ diretrizesreuni.pdf $>$ Acesso em 10 de dez. 2009.

Ministério da Educação e do

Desporto. Disponível em < http://reuni.mec.gov.br/ > . Acesso em: 20 set. 2009.

BRESSER-PEREIRA, L. C. Da

Administração pública burocrática à gerencial. In: BRESSER PEREIRA, L.C.B.; SPINK, P (Orgs.). Reforma do Estado e administração pública gerencial. Rio de Janeiro: FGV, p. 237-270, 2006. 
Da Administração Pública

Burocrática à Gerencial, Revista do

Serviço Público, 47(1) janeiro-abril 1996.

Reforma do Estado para a

Cidadania. A Reforma Gerencial

Brasileira na Perspectiva Internacional.

Brasília: ENAP/Editora 34, 1998.

CARDOSO, F.H. Reforma do Estado. In: BRESSER PEREIRA, L.C.B.; SPINK, P. (Orgs.) Reforma do Estado e

administração pública gerencial. Rio de Janeiro: FGV, 2006, p. 15-20.

CHAUÍ, M.. A Universidade Operacional. Folha de São Paulo, Caderno Mais. São Paulo - 9 de Maio de 1999. Disponível em $<$

http://reuniufpr.forumativo.com/document os-f1/a-universidade-operacional-marilenachaui-t46.htm > Acesso em 10 de dez. 2009.

A Universidade pública sob nova perspectiva. Revista Brasileira de Educação. Campinas, n. 24, p. 5-15, set/out/nov/dez. 2003.

CHAVES, V. L. J.. Reforma do Estado e Privatização da Universidade Pública Brasileira - Conseqüências sobre o Trabalho Docente. VI SEMINÁRIO DA REDESTRADO - Regulação Educacional e Trabalho Docente 06 e 07 de novembro de 2006 - UERJ. Anais.... Rio de Janeiro.

; LIMA, R. N.; MEDEIROS, L..

(2006). Política de Expansão,

Diversificação e Privatização da educação superior brasileira. In: XII SEMINÁRIO NACIONAL UNIVERSITAS/BR. Anais.... Brasília: Instituto Nacional de Estudos e Pesquisas Educacionais Anísio Teixeira.

; MENDES, O. C.. REUNI - O

Contrato de Gestão na Reforma da Educação Superior Pública. In: XXIV Simpósio Brasileiro, III Congresso
Interamericano de Política e Administração da Educação, 2009, Vitória. Direitos Humanos e Cidadania - desafios para as políticas e a gestão democrática da educação. Anais... Rio de Janeiro: Cadernos ANPAE no 8, 2009. p. 1-14.

CUNHA, L. A.. O desenvolvimento meandroso da educação brasileira entre o estado e o mercado. Educ. Soc. [online]. 2007, vol.28, n.100, pp. 809-829. ISSN 0101-7330.

DECLARAÇÃO DE BOLONHA. Declaração conjunta dos ministros da educação europeus. Assinada em Bolonha, 19 de Junho de 1999.

DECLARAÇÃO DE SORBONNE. Por ocasião do $800^{\circ}$ aniversário da Universidade de Paris, declaração conjunta dos quatro ministros responsáveis pelo Ensino Superior na Alemanha, França, Itália e Reino Unido. Paris, Sorbonne, 25 de Maio de 1998.

FAVERO, M. L. A.. Autonomia Universitária no Brasil: uma utopia? In: IV Congreso Iberoamericano de Historia de la Educación Latinoamericana, 2008, Santiago do Chile. Anais... Resumenes del IV Congreso Iberoamericano de Historia de la Educación Latinoamericana. Santiago do Chile, 2008. p. 103-104.

FILHO, M. C. F. Organizações e instituições: uma abordagem exploratória a partir de experiências de mudanças no setor público. Adcontar, Belém, v. 5, n.1. p. 15-34, junho, 2004.

FRIGOTTO, G.. Fundamentos científicos e técnicos da relação trabalho e educação no Brasil de hoje. In: LIMA, J. C.; NEVES, L. M. W. Fundamentos da educação escolar no Brasil contemporâneo. Rio de Janeiro: Fiocruz/EPSJV, 2005. p. 241-260.

GONÇALVES, S. M. S e SILVA JR, J. T. Por uma gestão social, ética e participativa: 
Construindo alternativas para "Um outro mundo possível”. In: III ENAPEGS.

Anais... Juazeiro/BA - Petrolina/PE. 2009.

KETTL, D. F. A revolução global: reforma da administração do setor público. In:

BRESSER

PEREIRA, L.C.B.; SPINK, P (Orgs.).

Reforma do Estado e administração

pública gerencial. Rio de Janeiro: FGV, 2006, p. 75-140.

LÉDA, D. B.; MANCEBO, D.. REUNI:

heteronomia e precarização da universidade e do trabalho docente.

Educação Realidade. 34(1): 49-64, jan/abril 2009.

LEITE, J. C. Fórum Social Mundial: a história de uma invenção política. São Paulo: Fundação Perseu Abramo, 2003.

LIMA, K. Reforma da educação superior brasileira nos anos de neoliberalismo: reformulações político-pedagógicas em curso nas universidades federais do estado do Rio de Janeiro. Escola de Serviço Social e Programa de Pós-Graduação em Educação - UFF, 2009.

LIMA, L. C.; AZEVEDO, M. L. N.; CATANI, A. M.. O Processo de Bolonha, A Avaliação da Educação Superior e Algumas Considerações sobre a Universidade Nova. Avaliação, Campinas; Sorocaba, SP, v. 13, n. 1, p. 7-36, mar. 2008.

MANCEBO, D.. Reforma universitária: reflexões sobre a privatização e a mercantilização do conhecimento. Educ. Soc. [online]. 2004, vol.25, n.88, pp. 845866. ISSN 0101-7330.

; MAUÉS, O.; CHAVES, V. L. J.. Crise e reforma do Estado e da Universidade Brasileira: implicações para o trabalho docente. Educar, Curitiba, n. 28, p. 37-53, 2006. Editora UFPR.
MATIAS-PEREIRA, José. Administração pública comparada: uma avaliação das reformas administrativas do Brasil, EUA e União Européia. Revista de Administração Pública. 42(1): 61-82, Jan/Fev. 2008.

OTRANTO, C. R.. A autonomia universitária como construção coletiva. In: $27^{a}$ Reunião Anual da ANPEd, 2004, Caxambú. Anais da 27ª ANPEd, 2004.

PAES DE PAULA, A. P. Administração Pública Brasileira: entre o gerencialismo e a gestão social. Revista de Administração de Empresas. São Paulo, 45(1): 36-52, Jan/Mar. 2005.

REZENDE, F. da C. Por que reformas administrativas falham? RBCS Vol. $17 \mathrm{~N}^{\circ}$ 50 outubro/2002.

SANTOS, B. S. A universidade no século XXI: para uma reforma democrática e emancipatória da universidade. Educação, Sociedade \& Culturas, Porto, Portugal, $\mathrm{n}$. 23, p. 137-202, 2005.

SAVATER, F. O valor de Educar. Trad. M. Stahel. São Paulo: Martins Fontes, 2000.

SHIROMA, E. O; et al.. Indicadores de Qualidade: o fetiche da gestão por resultados. VIII Seminário de Pesquisa em Educação da Região Sul, ANPEd SUL. Anais... Ijuí, 2008.

UNIVERSIDADE FEDERAL DA BAHIA - UFBA. Universidade Nova: Plano de Expansão e Reestruturação da Arquitetura Curricular na Universidade Federal da Bahia. Texto preliminar estabelecido com a finalidade de subsidiar debates conceituais e metodológicos sobre o tema em pauta. 2007. Disponível em $<$ http://www2.faced.ufba.br/noticias/notici as/universidadenova25102006 > Acesso em 10 de dezembro de 2009. 